ISSN 1808-3765

\title{
LÂMINAS DE FERTIRRIGAÇÃO E SUBSTRATOS NA PRODUÇÃO E QUALIDADE DE GÉRBERA DE VASO
}

\author{
FERNANDA LUDWIG'; AMARALINA CELOTO GUERRERO ${ }^{2}$; SIMONE DE \\ OLIVEIRA GONÇALVES ${ }^{3}$; DIRCEU MAXIMINO FERNANDES ${ }^{2}$ E ROBERTO \\ LYRA VILLAS BÔAS ${ }^{2}$
}

${ }^{1}$ UERGS, Av. Independência, 2824, 96815-900 - Santa Cruz do Sul-RS, ludwig.fernanda@yahoo.com.br.; ${ }^{2}$ FCA/UNESP - Departamento de Recursos Naturais, Rua José Barbosa de Barros, 1780, 18610-307 - BotucatuSP, maracguerrero@ hotmail.com,dmfernandes@fca.unesp.br, rlvboas@fca.unesp.br.

${ }^{3}$ FCA/UNESP - Departamento de Engenharia Rural, Rua José Barbosa de Barros, 1780, 18610-307 - BotucatuSP, simone-say@hotmail.com.

\section{RESUMO}

O manejo da fertirrigação para a cultura da gérbera, muitas das vezes, ocorre de forma inadequada, ainda mais quando são utilizadas misturas de substratos com características físicas e químicas distintas. Com o objetivo de avaliar a produção e a qualidade de gérbera de vaso em dois substratos e lâminas de fertirrigação, o experimento foi conduzido em casa de vegetação do Departamento de Recursos Naturais/Ciência do Solo, na FCA/UNESP, município de Botucatu (SP). Adotou-se o delineamento em blocos casualizados, em fatorial 5x2 (5 lâminas de fertirrigação e 2 substratos), com 4 repetições. Os níveis de fertirrigação corresponderam à manutenção de $100 \%$ da água disponível (AD) no substrato; 100 a $80 \%$ da $\mathrm{AD} ; 100$ a $60 \%$ da $\mathrm{AD} ; 100$ a $40 \%$ da $\mathrm{AD} ; 100$ a $20 \%$ da AD. Os substratos utilizados foram: 1- fibra de coco mista (50\% fibra de coco granulada e 50\% fibra de coco fibrosa), 2- $40 \%$ terra vermelha, $40 \%$ casca de pinus decomposta, $10 \%$ composição 1 (40\% casca de pinus decomposta, $30 \%$ vermiculita e $30 \%$ casca de arroz carbonizada) e $10 \%$ composição 2 (75\% casca de pinus decomposta e $25 \%$ acícula de pinus). As plantas em ponto de comercialização foram avaliadas quanto ao número de folhas, diâmetro da superfície foliar da planta, área foliar, fitomassa fresca e seca das folhas, das inflorescências e total, número e diâmetro das inflorescências, diâmetro da haste, altura de planta, razão de área foliar e condutividade elétrica da solução do substrato. As plantas de melhor qualidade foram obtidas quando mantidas na lâmina de $100 \%$ de água disponível e o uso da fibra de coco mista como substrato.

Palavras-chave: Gerbera jamesonii L., floricultura, irrigação.

\section{LUDWIG, F.; GUERRERO, A.C.; GONÇALVES, S.O.; FERNANDES, D.M.; VILLAS BÔAS, R.L. \\ FERTIGATION LEVELS AND SUBSTRATES ON THE PRODUCTION AND QUALITY OF POTTED GERBERA}

\section{ABSTRACT}

Fertigation management of gerbera crop has been many times performed inadequately, and it has been worsened when mixtures of substrates with different physical and chemical 
characteristics are used. Aiming at evaluating the production and quality of potted gerbera in two substrates and different levels of fertigation, the experiment was conducted in the greenhouse of the DRN/Soil Science, FCA/UNESP, Botucatu (SP). A 5 x 2 factorial randomized block design (5 levels of fertigation and 2 substrates) was adopted with 4 replications. Levels of fertigation corresponded to maintenance of $100 \%$ available water (AW) in the substrate; 100 to $80 \%$ of AW; 100 to $60 \%$ of AW; 100 to $40 \%$ of AW and 100 to $20 \%$ of AW. The substrates were as follows: 1 - mixed coconut fiber (50\% pellet coconut fiber and 50\% coir fiber), $2-40 \%$ red soil, $40 \%$ decomposed pine bark, $10 \%$ composition 1 (40\% decomposed pine bark, 30\% vermiculite and 30\% carbonized rice husk) and 10\% composition 2 (75\% decomposed pine bark and $25 \%$ needles of pine). Plants at the marketing stage were evaluated according to the number of leaves; diameter of leaf surface; leaf area; fresh and dry phytomass of leaves, inflorescence and total plant; inflorescence number and diameter, stem diameter, plant height, leaf area rate and electrical conductivity of the substrate solution. Plants of better quality were obtained when they were maintained in levels of $100 \%$ available water and the mixed coconut fiber was used as substrate.

Keywords: Gerbera jamesonii L., floriculture, irrigation.

\section{INTRODUÇÃO}

A gérbera (Gerbera jamesonii L.) é uma planta herbácea pertencente à família Asteraceae que tem sua origem no sul da África e Ásia, a partir da qual foram obtidos inúmeros híbridos de diversas combinações de cores e formas de suas inflorescências, que a tornou muito interessante ao mercado consumidor (Radice \& Marconi, 1998). Atualmente destaca-se pela grande importância econômica, entre as várias espécies ornamentais cultivadas (Guerrero et al., 2012).

Plantas conduzidas em vaso têm limitação ao crescimento das raízes, e assim, o substrato deve apresentar características físicas e químicas adequadas para compensar essa desvantagem. Dentre as características do substrato adequadas para a gérbera cultivada em vaso, Ludwig et al. (2010a) destacam o pH, que deve ser mantido entre 5,5 e 7,0 e a densidade seca, que deve ser inferior a $530 \mathrm{~kg} \mathrm{~m}^{-3}$.

O espaço de aeração é geralmente considerado como um fator determinante da qualidade dos substratos (Sahin \& Anapali, 2006). Segundo Bellé (2001), substratos bem aerados permitem o bom desenvolvimento de pelos radiculares, o que aumenta a absorção de nutrientes e água.

O principal objetivo da fertirrigação é fornecer água e nutrientes em quantidades suficientes e em momentos adequados visando atender às necessidades hídricas e nutricionais da planta, garantindo assim, o aumento da produtividade e a melhoria na qualidade da produção. O tempo requerido e a quantidade de água aplicada são influenciados pelas condições climáticas, tipo de cultura, estádio de crescimento das plantas e capacidade de retenção de água do substrato (Papadopoulos et al., 1995).

O grande número de substratos disponíveis com características diferentes pode dificultar o processo de fertirrigação, pela sua influência direta com as características físicas de aeração e retenção de água. Desse modo, o presente trabalho foi conduzido com o objetivo de avaliar a produção e qualidade de gérbera de vaso em dois substratos e lâminas de fertirrigação. 


\section{MATERIAL E MÉTODOS}

O experimento foi realizado no período de setembro a outubro de 2008, em casa de vegetação do Departamento de Recursos Naturais, Área de Ciência do Solo, na FCA UNESP, município de Botucatu (22 $51^{\prime}$ 'S; $48^{\circ} 26^{\prime} \mathrm{W}$ ), estado de São Paulo. A temperatura média no interior da casa de vegetação foi de $23^{\circ} \mathrm{C}$ e a umidade relativa média do ar de $63 \%$.

A casa de vegetação apresenta estrutura tipo arco, coberto com plástico transparente de $150 \mu \mathrm{m}$, laterais de tela branca, cortinas de plástico transparente, em uma área total de $168,0 \mathrm{~m}^{2}(7,0 \times 24,0 \mathrm{~m})$ e 2,6 $\mathrm{m}$ de pé direito. Instalou-se internamente, na parte superior, uma malha aluminizada termorrefletora removível, para que a cultura fosse conduzida na intensidade luminosa máxima de 50 mil lx (Mercurio, 2002).

Adotou-se o delineamento experimental em blocos casualizados, em esquema fatorial 5x2 (cinco lâminas de fertirrigação e dois substratos) e quatro repetições. Os substratos utilizados foram: 1 - fibra de coco mista (50\% fibra de coco granulada e $50 \%$ fibra de coco fibrosa), 2 - 40\% terra vermelha (Latossolo Vermelho Escuro), $40 \%$ casca de pinus decomposta, $10 \%$ composição 1 (40\% casca de pinus decomposta, $30 \%$ vermiculita e $30 \%$ casca de arroz carbonizada) e 10\% composição 2 (75\% casca de pinus decomposta e $25 \%$ acícula de pinus). A terra vermelha apresentou a seguinte composição química: $\mathrm{pH}\left(\mathrm{CaCl}_{2}\right)$ : 4,1; P (resina): $5 \mathrm{mg} \mathrm{dm}{ }^{-3}$; $\mathrm{H}+\mathrm{Al}: 5,2 \mathrm{cmol}_{\mathrm{c}} \mathrm{dm}^{-3} ; \mathrm{K}: 0,22 \mathrm{cmol}_{\mathrm{c}} \mathrm{dm}^{-3} ; \mathrm{Ca}: 1 \mathrm{cmol}_{\mathrm{c}} \mathrm{dm}^{-3}$; Mg: 0,5 $\mathrm{cmol}_{\mathrm{c}} \mathrm{dm}^{-3}$; SB: 1,72 $\mathrm{cmol}_{\mathrm{c}} \mathrm{dm}^{-3}$; CTC: $6,92 \mathrm{cmol}_{\mathrm{c}} \mathrm{dm}^{-3} ; \mathrm{V}(\%): 24,86 \mathrm{cmol}_{\mathrm{c}} \mathrm{dm}^{-3}$; B: $0,2 \mathrm{mg} \mathrm{dm}^{-3}$; Cu: $0,5 \mathrm{mg} \mathrm{dm}^{-3}$; Fe: $42,5 \mathrm{mg} \mathrm{dm}^{-3}$; Mn: $0,5 \mathrm{mg} \mathrm{dm}^{-3}$; Zn: $0,8 \mathrm{mg} \mathrm{dm}^{-3}$. As características químicas de condutividade elétrica (CE) e $\mathrm{pH}_{1: 5}$ (Brasil, 2007), macronutrientes e micronutrientes ${ }_{1: 1,5}$ (Sonneveld \& Elderen, 1994) e físicas de densidade (Brasil, 2007) e retenção de água (De Boodt \& Verdonck, 1972) dos substratos são apresentadas na Tabela 1.

Tabela 1. Características físicas e químicas dos substratos utilizados no experimento.

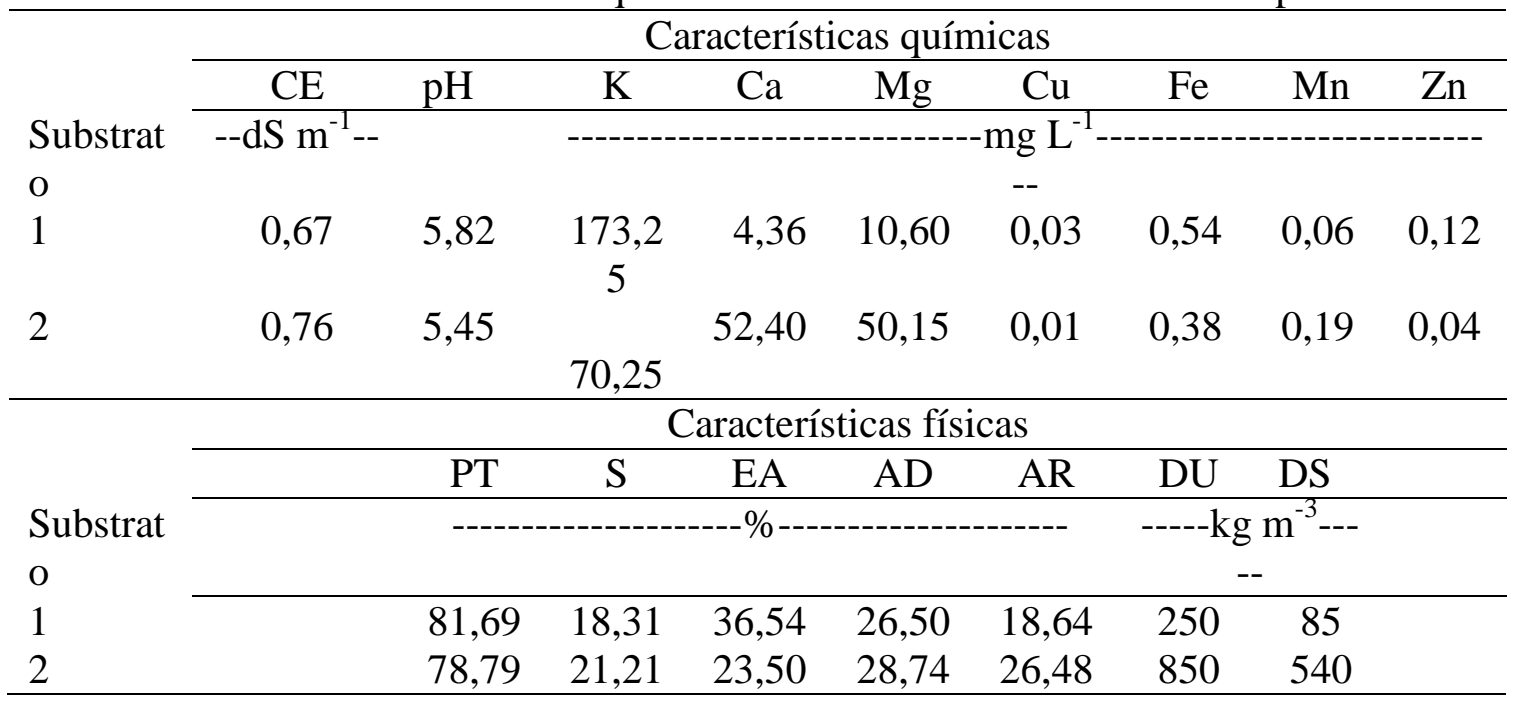

Substratos: 1 - fibra de coco mista (50\% fibra de coco granulada e 50\% fibra de coco fibrosa), 2 - 40\% terra vermelha, $40 \%$ casca de pinus decomposta, 10\% composição 1 (40\% casca de pinus decomposta, $30 \%$ vermiculita e $30 \%$ casca de arroz carbonizada) e $10 \%$ composição 2 ( $75 \%$ casca de pinus decomposta e $25 \%$ acícula de pinus). CE: condutividade elétrica. PT: porosidade total. S: sólidos. EA: espaço de aeração. AD: água disponível. AR: água remanescente. DU: densidade úmida. DS: densidade seca. 
A unidade experimental consistiu de um vaso plástico $(11,5 \mathrm{~cm}$ de altura, $13,0 \mathrm{~cm}$ de diâmetro superior e 9,0 cm de diâmetro inferior), preenchido com o substrato correspondente ao tratamento, de acordo com a densidade úmida (Tabela 1), com uma planta cada. Foram utilizadas mudas de gérbera (Gerbera jamesonii L), cultivar Cherry, com aproximadamente 30 dias e quatro folhas definitivas, as quais permaneceram em aclimatação por mais 30 dias. Após esse período, os tratamentos de fertirrigação foram iniciados.

Para determinar a capacidade máxima de retenção de água dos substratos, ou capacidade do recipiente, os vasos foram saturados por capilaridade durante 24 horas com posterior drenagem nas 24 horas subsequentes, e então pesados. A capacidade mínima de retenção foi determinada pela pesagem do vaso após a morte de uma planta de gérbera por murcha permanente.

O manejo da fertirrigação baseou-se na pesagem diária dos vasos. A lâmina necessária para a reposição hídrica estabeleceu-se pela diferença entre a massa obtida na capacidade máxima de retenção do substrato (100\% de água disponível (AD)) e a capacidade mínima de retenção, variável de acordo com o substrato. Durante o período de aclimatação, a lâmina de fertirrigação foi mantida entre 25 e $50 \%$ da $\mathrm{AD}$ no substrato. No período experimental, as lâminas de fertirrigação aplicadas foram mantidas de acordo com cada tratamento: 1 - manutenção de $100 \%$ da AD no substrato; 2 - 100 a $80 \%$ da AD; 3 - 100 a $60 \%$ da $\mathrm{AD} ; 4-100$ a $40 \%$ da $\mathrm{AD} ; 5-100$ a $20 \%$ da AD. Efetuou-se a fertirrigação quando a massa do vaso fosse igual ou inferior à massa correspondente à capacidade mínima de retenção mais o limite inferior de $\mathrm{AD}$ em cada tratamento, elevando novamente para a massa correspondente à capacidade mínima de retenção $+100 \%$ da água disponível no substrato. As fertirrigações foram aplicadas manualmente com o uso de recipientes graduados.

A quantidade total de solução aplicada para a fibra de coco, nas lâminas de 100, 80, 60,40 e $20 \%$ foi de $1,67 \mathrm{~L}, 1,31 \mathrm{~L} ; 1,25 \mathrm{~L} ; 1,08 \mathrm{~L} ; 0,90 \mathrm{~L}$, respectivamente. Para o substrato contendo terra vermelha, a quantidade total de solução nas lâminas foi de 2,09 L; 1,79 L; $2,06 \mathrm{~L} ; 1,77 \mathrm{~L} ; 1,37 \mathrm{~L}$. A solução nutritiva apresentou a seguinte composição em $\mathrm{mg} \mathrm{L}^{-1}: 121 \mathrm{~N}^{-\mathrm{NO}_{3}}{ }^{-}, 12 \mathrm{~N}^{-\mathrm{NH}_{4}}{ }^{+}, 92 \mathrm{~K}, 24 \mathrm{P}, 175 \mathrm{Ca}, 27 \mathrm{Mg}$ e $39 \mathrm{~S}$, no período vegetativo e $168 \mathrm{~N}^{-N_{3}}{ }_{3}^{-}, 41 \mathrm{~N}^{-\mathrm{NH}_{4}}{ }^{+}, 303 \mathrm{~K}, 35 \mathrm{P}, 105 \mathrm{Ca}, 45 \mathrm{Mg}$ e $55 \mathrm{~S}$, no período reprodutivo. As soluções foram ajustadas daquelas utilizadas por empresas produtoras de gérbera de vaso.

As plantas em ponto de comercialização, caracterizado pela abertura de duas fileiras de estames nas inflorescências (Lin \& French, 1985), foram avaliadas quanto ao número de folhas, diâmetro da superfície foliar da planta, área foliar, fitomassa fresca e seca das folhas, inflorescências e total, número e diâmetro das inflorescências, diâmetro da haste e altura de planta.

O diâmetro da superfície foliar da planta foi medido com o auxílio de régua graduada em milímetros, a partir de duas extremidades opostas da planta, perpendiculares entre si. A área foliar foi obtida em medidor tipo "scanner" modelo Li 3100, procedendo-se em seguida a determinação da fitomassa fresca em balança digital. Após, a parte aérea das plantas foi lavada, acondicionada em sacos de papel e posta em estufa de ventilação forçada a $65^{\circ} \mathrm{C}$ por um período médio de 48 horas, até massa constante, a fim de que fosse obtida sua fitomassa seca, em balança digital.

O diâmetro da haste foi aferido aos 5,0 cm abaixo da inflorescência, com auxílio de paquímetro digital. Para obtenção do diâmetro de inflorescência, adotaram-se dois pontos extremos, medido com o uso de paquímetro digital. A altura da planta foi mensurada com auxílio de régua graduada em milímetros, a partir da parte superior do vaso até a extremidade da planta. 
Determinou-se a razão de área foliar de acordo com Benincasa (2003). A CE da solução do substrato foi avaliada utilizando-se o método 'pourthru' (Cavins et al., 2004). O método consiste em saturar o vaso com a solução nutritiva, o qual é deixado em repouso por um período de uma hora, quando então recebe um coletor na sua parte inferior e a adição de $90 \mathrm{~mL}$ de água destilada na porção superior. A água destilada desloca a solução da parte inferior do vaso, para que seja coletada e analisada.

Os efeitos dos tratamentos foram submetidos ao teste Tukey a 5\% de probabilidade, para os substratos e à análise de regressão para as lâminas de fertirrigação. Testaram-se os modelos lineares e quadráticos, adotando a equação de regressão que melhor se ajustou aos dados, a qual foi escolhida com base na significância a $1 \%(* *)$ e $5 \%(*)$ de probabilidade pelo teste $\mathrm{F}$ e no maior valor do coeficiente de determinação $\left(\mathrm{R}^{2}\right)$.

\section{RESULTADOS E DISCUSSÃO}

A análise de variância demonstrou que não houve interação entre substratos e lâminas de fertirrigação (Tabelas 2 e 3), para todas as variáveis analisadas, indicando que os dados médios são representativos das respostas obtidas.

Tabela 2. Número de folhas (NF), diâmetro da superfície foliar da planta (DP), área foliar $(\mathrm{AF})$, fitomassa fresca das folhas (FFF), fitomassa fresca da inflorescência (FFI), fitomassa fresca total (FFT), fitomassa seca das folhas (FSF), fitomassa seca das inflorescências (FSI), fitomassa seca total (FST), em função dos substratos e das lâminas de fertirrigação.

\begin{tabular}{lccccccccc}
\hline & NF & DP & AF & FFF & FFI & FFT & FSF & FSI & FST \\
\hline Substrat & & $-\mathrm{cm}-$ & $--\mathrm{cm}^{2}--$ & ---------------------- g-------------------- \\
o & & & & & & & & & \\
1 & 19,5 & $32,9 \mathrm{a}$ & $880,7 \mathrm{a}$ & $37,9 \mathrm{a}$ & $25,0 \mathrm{a}$ & $62,9 \mathrm{a}$ & 5,4 & 3,7 & 9,0 \\
2 & 21,2 & $28,1 \mathrm{~b}$ & $711,5 \mathrm{~b}$ & $30,2 \mathrm{~b}$ & $18,9 \mathrm{~b}$ & $49,2 \mathrm{~b}$ & 5,4 & 3,4 & 8,8 \\
\hline $\mathrm{L}$ & $* *$ & $\mathrm{NS}$ & $* *$ & $* *$ & $\mathrm{NS}$ & $* *$ & $* *$ & $\mathrm{NS}$ & $* *$ \\
$\mathrm{~S}$ & $\mathrm{NS}$ & $* *$ & $*$ & $*$ & $*$ & $* *$ & $\mathrm{NS}$ & $\mathrm{NS}$ & $\mathrm{NS}$ \\
$\mathrm{L} * \mathrm{~S}$ & $\mathrm{NS}$ & $\mathrm{NS}$ & $\mathrm{NS}$ & $\mathrm{NS}$ & $\mathrm{NS}$ & $\mathrm{NS}$ & $\mathrm{NS}$ & $\mathrm{NS}$ & $\mathrm{NS}$ \\
$\mathrm{CV}(\%)$ & 22,39 & 10,48 & 25,61 & 25,73 & 41,45 & 24,31 & 24,72 & 42,16 & 23,10 \\
\hline
\end{tabular}

Valores seguidos pela mesma letra na coluna não diferem entre si pelo teste Tukey a 5\%. NS: não significativo; ** significativo a $1 \%$; * significativo a $5 \%$; L: lâmina. S: substratos. Substratos: 1 - fibra de coco mista (50\% fibra de coco granulada e 50\% fibra de coco fibrosa), 2 - 40\% terra vermelha, 40\% casca de pinus decomposta, 10\% composição 1 (40\% casca de pinus decomposta, $30 \%$ vermiculita e $30 \%$ casca de arroz carbonizada) e $10 \%$ composição 2 ( $75 \%$ casca de pinus decomposta e $25 \%$ acícula de pinus). 
Tabela 3. Número de inflorescências (NI), diâmetro de inflorescência (DI), diâmetro de haste (DH) altura de planta (A), razão de área foliar (RAF) e condutividade elétrica da solução do substrato (CE), em função dos substratos e das lâminas de fertirrigação.

\begin{tabular}{|c|c|c|c|c|c|c|}
\hline & NI & DI & DH & A & RAF & CE \\
\hline Substrato & & \multicolumn{2}{|c|}{---------mm--------- } & $--\mathrm{cm}--$ & $--\mathrm{dm}^{2} \mathrm{~g}^{-1}-$ & $--\mathrm{dS} \mathrm{m} \mathrm{m}^{-1}$ \\
\hline 1 & 2,5 & $85,7 \mathrm{a}$ & 4,5 & $19,9 \mathrm{a}$ & $0,97 \mathrm{a}$ & $3,43 \mathrm{a}$ \\
\hline 2 & 2,0 & $77,5 \mathrm{~b}$ & 4,1 & $15,7 \mathrm{~b}$ & $0,82 \mathrm{~b}$ & $2,91 \mathrm{~b}$ \\
\hline $\mathrm{L}$ & NS & NS & NS & NS & NS & NS \\
\hline S & NS & $* *$ & NS & $* *$ & $* *$ & $* *$ \\
\hline $\mathrm{L} * \mathrm{~S}$ & NS & NS & NS & NS & NS & NS \\
\hline R L & NS & NS & NS & NS & NS & NS \\
\hline $\mathrm{CV}(\%)$ & 59,22 & 8,32 & 14,64 & 21,68 & 19,26 & 14,49 \\
\hline
\end{tabular}

Valores seguidos pela mesma letra na coluna não diferem entre si pelo teste Tukey a 5\%. NS: não significativo; ** significativo a $1 \%$; * significativo a $5 \%$; L: lâmina. S: substratos. Substratos: 1 - fibra de coco mista (50\% fibra de coco granulada e 50\% fibra de coco fibrosa), 2 - 40\% terra vermelha, $40 \%$ casca de pinus decomposta, 10\% composição 1 (40\% casca de pinus decomposta, $30 \%$ vermiculita e $30 \%$ casca de arroz carbonizada) e $10 \%$ composição 2 ( $75 \%$ casca de pinus decomposta e $25 \%$ acícula de pinus).

O número de folhas não variou significativamente nas plantas em função dos substratos, entretanto, aumentou linearmente com a lâmina de fertirrigação (Tabela 2, Figura 1). Parizi et al. (2010) e Pereira et al. (2003) em estudo com lâminas de irrigação para a cultura do kalanchoe (Kalanchoe blossfeldiana) e do crisântemo (Dendranthema grandiflora), respectivamente, verificaram que o estresse hídrico reduziu o número de folhas, corroborando os resultados obtidos neste experimento. De acordo com Taiz \& Zeiger (2009), o déficit hídrico limita o número de folhas, o que pode ser considerada uma resposta da planta para evitar a perda de água por transpiração e garantir sua sobrevivência em períodos de estresse.

Os maiores diâmetros da superfície foliar da planta (DP) foram registrados naquelas conduzidas no substrato de fibra de coco (Tabela 2), que alcançaram $32,9 \mathrm{~cm}$, não sendo influenciado pelas lâminas de fertirrigação. Neste substrato, as plantas também apresentaram maior área foliar, com valores de $880,7 \mathrm{~cm}^{2}$ (Tabela 2). Segundo Ludwig et al. (2011) o diâmetro da superfície foliar de planta e a área foliar são características importantes para a comercialização da gérbera de vaso, sugerindo o diâmetro entre 29,0 a 31,0 cm e área foliar superior a 1000,0 $\mathrm{cm}^{2}$ como ideais. Desse modo, pode-se considerar mais adequada, as plantas conduzidas no substrato de fibra de coco, bem como a manutenção da lâmina de fertirrigação em $100 \%$ da AD no substrato. 

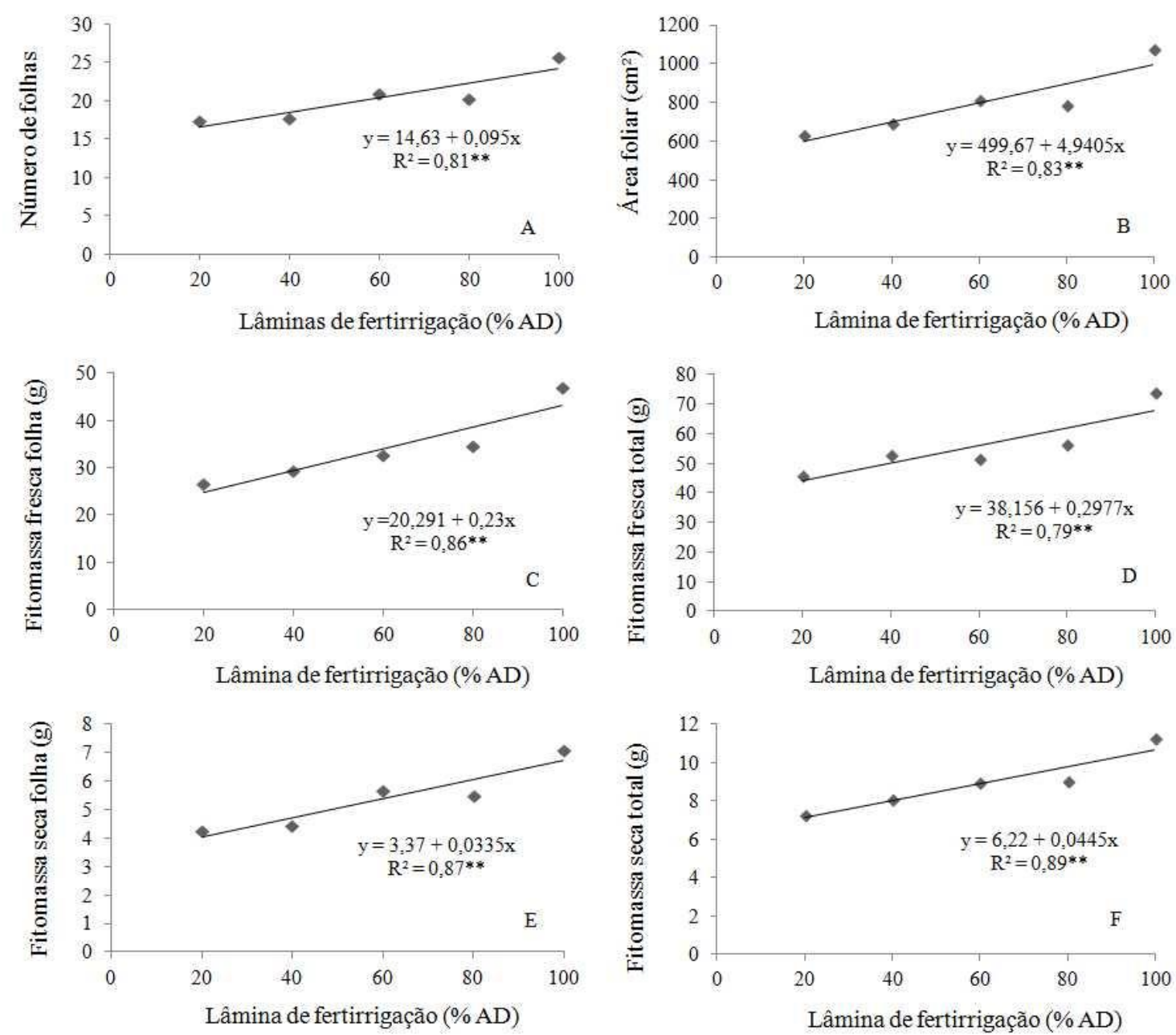

Figura 1. Número de folhas (A), área foliar (B), fitomassa fresca da folha (C), fitomassa fresca total (D), fitomassa seca da folha (E) e fitomassa seca total (F) em plantas de gérbera, em função das lâminas de fertirrigação.

As propriedades físicas da fibra de coco (Tabela 1) podem ter influenciado nas respostas positivas das plantas. De acordo com Rogers \& Tjia (1990), o substrato para a gérbera deve apresentar elevada capacidade de retenção de água, mas ao mesmo tempo possuir macroporos para facilitar a rápida drenagem após a irrigação. Estas características foram observadas no substrato de fibra de coco, com água disponível de $26,5 \%$ e espaço de aeração de $36,5 \%$, permitindo o suprimento de água e a oxigenação do ambiente radicular.

A maior densidade do substrato 2 está relacionada à menor porosidade total, menor espaço de aeração e maior proporção de sólidos (Tabela 1). A elevada densidade dificulta o crescimento radicular, especialmente em vasos de tamanho reduzido (Ludwig et al., 2010a), o que pode ter refletido na menor qualidade das plantas nesse substrato (Figura 2). 

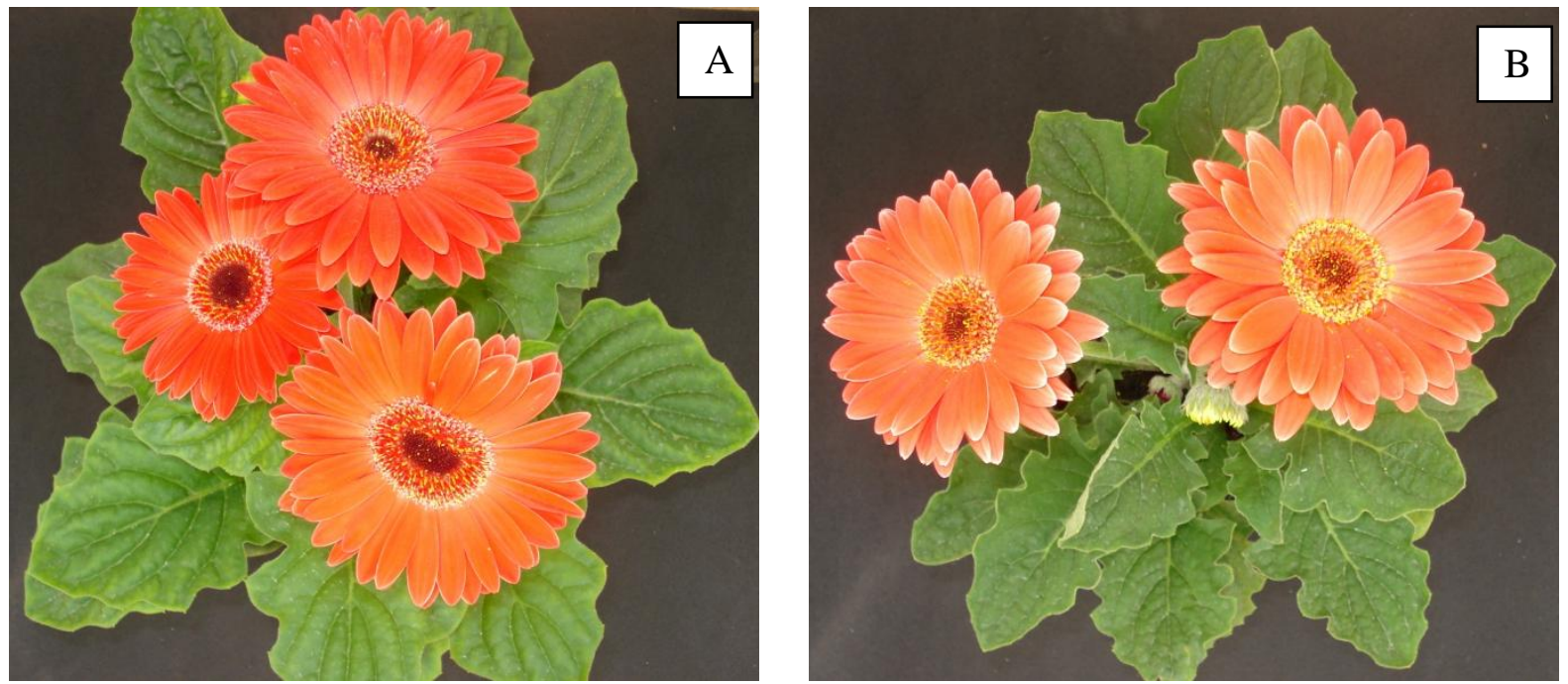

Figura 2. Planta de gérbera conduzida no substrato composto por fibra de coco (A) e no substrato composto por terra vermelha e casca de pinus decomposta (B).

A área foliar aumentou linearmente com o incremento da lâmina de fertirrigação (Figura 3), com $445 \mathrm{~cm}^{2}$ adicionais quando relacionada à menor e a maior lâmina, refletindo também na fitomassa fresca e seca da folha (Figura 1). De acordo com Taiz \& Zeiger (2009), a redução da área foliar pode ser considerada a primeira linha de defesa contra a seca, pela menor transpiração, conservando o suprimento de água no solo por mais tempo. De acordo com os autores, à medida que o conteúdo de água na planta decresce, reduz-se a pressão de turgor contra as paredes celulares, limitando a expansão celular e consequentemente a área foliar.
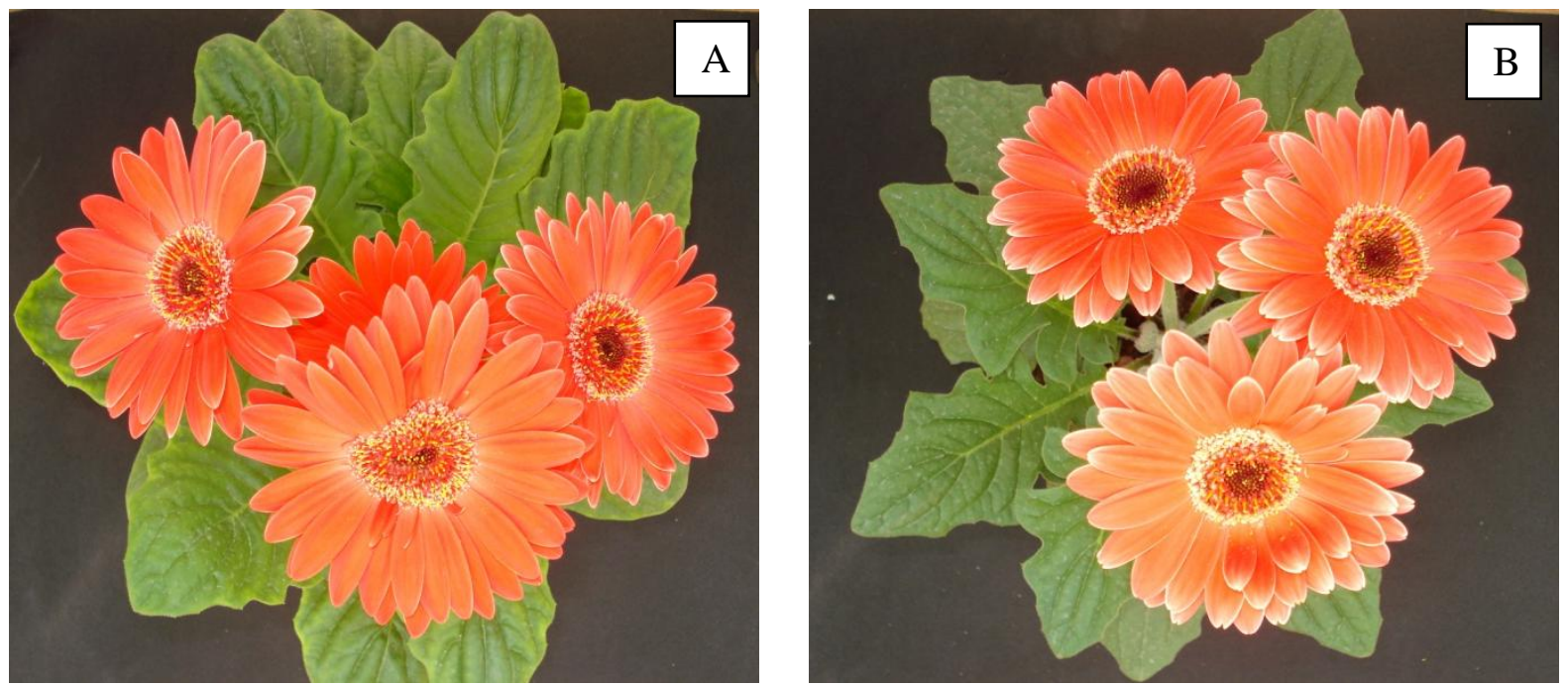

Figura 3. Planta de gérbera conduzida na lâmina de $100 \%$ da água disponível (A) e 100 a $20 \%$ da água disponível (B).

Os maiores valores de fitomassa fresca da folha $(37,9 \mathrm{~g})$, inflorescência $(25,0 \mathrm{~g}) \mathrm{e}$ total $(62,9 \mathrm{~g})$ foram obtidos nas plantas conduzidas com o substrato de fibra de coco. Entretanto, a fitomassa seca destes mesmos órgãos não apresentou o mesmo comportamento (Tabela 2), indicando que as plantas nesse substrato apresentaram maior conteúdo de água.

A fitomassa fresca e seca da inflorescência (Tabela 2), o número e o diâmetro da inflorescência, a altura e o diâmetro de haste (Tabela 3) não foram influenciados pelas 
lâminas de fertirrigação. Os resultados indicam que as características reprodutivas são menos afetadas que as vegetativas quanto ao déficit hídrico, podendo estar relacionado à economia de água durante o período vegetativo, permitindo assim que as plantas utilizem a energia para atingir a produção (Santos \& Carlesso, 1998).

A fitomassa fresca total (Tabela 2) foi superior naquelas plantas conduzidas no substrato de fibra de coco $(62,9 \mathrm{~g})$ comparado com o substrato com terra vermelha $(49,2 \mathrm{~g})$. Essa tendência, porém, não foi verificada para a fitomassa seca total, indicando maior acumulo de água naquelas no substrato de fibra de coco. A fitomassa fresca total aumentou linearmente em função da lâmina de fertirrigação (Figura 1), em função da maior disponibilidade hídrica.

A altura de planta foi superior no substrato de fibra de coco, com valor médio de $19,9 \mathrm{~cm}$ (Tabela 3). Resultados superiores para a mesma cultivar, foram registrados por Ludwig et al. (2010b), com 29,7 cm, entretanto, com ciclo de crescimento de 62 dias. Pereira et al. (2003) ao avaliarem o crescimento de crisântemo conduzido em vaso sob níveis de reposição de água, verificaram redução na altura da planta conduzida em maiores déficit hídrico, discordando dos resultados obtidos no presente trabalho. Cabe ressaltar que espécies diferentes podem ter respostas diferentes.

O diâmetro de inflorescência, característica que segundo Ludwig et al. (2011) é decisiva na seleção de plantas de gérbera por consumidores, foi significativamente superior nas plantas conduzidas no substrato de fibra de coco (Tabela 3). O diâmetro das hastes não variou em função dos substratos e tanto o diâmetro de inflorescências quanto o de hastes não foram influenciadas pela lâmina de fertirrigação (Tabela 3). O diâmetro de haste relaciona-se à sustentação das inflorescências, evitando o possível tombamento e perda de qualidade, principalmente durante transporte e manuseio (Ludwig et al., 2011).

A razão de área foliar (RAF) é a área foliar útil para a fotossíntese, apresentando a razão entre a área responsável pela interceptação de energia luminosa e $\mathrm{CO}_{2}$ e a fitomassa seca total (Benincasa, 2003). A maior RAF foi observada nas plantas conduzidas no substrato $1\left(0,97 \mathrm{dm}^{2} \mathrm{~g}^{-1}\right)$, indicando que a maior área foliar não resultou em sombreamento e redução da área fotossintetizante, refletindo em maior quantidade de material fotossintetizado convertido para as folhas, o que concorda com os resultados de área foliar, diâmetro de planta e fitomassa fresca das folhas obtidos no experimento. Nesse sentido, a RAF é uma característica importante, pois a formação de folhas contribui para a qualidade visual de plantas envasadas. Diferença entre substratos, para a RAF de plantas de gérbera das cultivares Cherry e Red, foram registradas por Ludwig et al. (2010a), com menores valores em substrato contendo terra vermelha na composição, devido às características de reduzido $\mathrm{pH}$ e elevada densidade deste substrato, concordando com os resultados obtidos.

Os valores de CE da solução do substrato, ao final do ciclo (Tabela 3) não diferiram significativamente entre as lâminas de fertirrigação, indicando que os resultados não são decorrentes de maior ou menor fornecimento de nutrientes, mas sim da disponibilidade hídrica. Porém, a CE da solução do substrato composto de fibra de coco foi significativamente superior àquele contendo terra vermelha, indicando que este pode ter retido parte dos nutrientes fornecidos via solução nutritiva, já que a densidade e a quantidade de água remanescente era superior (Tabela 1).

Os resultados obtidos permitem inferir que a manutenção das plantas na capacidade de recipiente $(100 \%$ da $\mathrm{AD})$ contribuiu para que as mesmas apresentassem melhores características de produção e qualidade. Segundo Bellé (1998), vários trabalhos recomendam a manutenção do substrato sob máxima retenção de água. À medida que a disponibilidade hídrica no substrato é reduzida, aumenta a dificuldade das plantas em absorver água, 
principalmente naqueles formados por partículas de tamanho reduzido, onde os microporos mantêm a água retida com maior tensão. Farias et al. (2004), analisando o efeito do déficit hídrico na cultura do crisântemo de vaso, obtiveram maior porcentagem de plantas com alta qualidade em menores tensões de água no substrato.

A fibra de coco apresentou densidade inferior e maior espaço de aeração, em relação ao substrato contendo terra vermelha (Tabela 1), características importantes que podem ter contribuído para seu efeito positivo no desenvolvimento das plantas. $\mathrm{O}$ espaço de aeração dos dois substratos testados foi favorável para a cultura da gérbera em vaso, entretanto, a densidade mais adequada seria a fornecida pela fibra de coco, pela possibilidade de trocas gasosas, removendo o gás carbônico e suprindo o oxigênio para o ambiente radicular das plantas. As características químicas iniciais tiveram pouca interferência nas respostas finais, já que a principal forma de fornecimento dos nutrientes ocorria via fertirrigação, aplicada diariamente.

Plantas conduzidas em vaso possuem reduzido espaço disponível para o crescimento das raízes, e isso ocorre de forma mais acentuada quando o substrato apresenta elevada densidade, pois há uma maior quantidade de sólidos por unidade de volume. Assim, um substrato ideal apresenta a característica de fornecer água para a planta, sem comprometer a oxigenação no ambiente radicular (Noodergraaf, 1994), características estas fornecidas pela fibra de coco.

\section{CONCLUSÃO}

A manutenção da lâmina de $100 \%$ da água disponível e a utilização do substrato de fibra de coco mista são mais adequados para a produção de plantas de gérbera envasada, conferindo as mesmas uma melhor qualidade visual.

\section{REFERÊNCIAS BIBLIOGRÁFICAS}

\section{BELLÉ, S. Sistemas de irrigação e concentrações de adubação complementar na} produção de gérbera jamesonii cv. 1187 em vaso. 1998. 122p. Tese (Doutorado em Fitotecnia), Universidade Federal do Rio Grande do Sul, Porto Alegre.

BELLÉ, S. Escolha do substrato. In: KÄMPF AN (coord). Manutenção de plantas ornamentais para interiores. Porto Alegre: Rígel, p.31-36. 2001.

BENINCASA, M. M. P. Análise de crescimento de plantas (noções básicas). Jaboticabal: FUNEP, 41p. 2003.

BRASIL. 2007. Instrução Normativa n.17, de 21 de maio de 2007. Aprova os Métodos Analíticos Oficiais para Análise de Substratos e Condicionadores de Solos. Diário Oficial da União, Brasília, 24 maio. Seção 1, p.8. 2007.

CAVINS, T.J.; WHIPKER, B.E.; FONTENO, W.C. Establishment of calibration curves for comparing pour-through and saturated media extract nutrient values. HortScience, Alexandria, v.39, n.7, p.1635-1639, 2004. 
De BOODT, M.; VERDONCK, O. The physical properties of the substrates in horticulture. Acta Horticulturae, Wageningen, v.1, n.23, p.37-44, 1972.

FARIAS, M.F. de; SAAD, J.C.C.; VILLAS BOAS, R.L. Manejo da irrigação na cultura do crisântemo em vaso, cultivar Rage, cultivado em ambiente protegido. Engenharia Agrícola, Jaboticabal, v.24, n.1, p.51-56, 2004.

GUERRERO, A.C.; FERNANDES, D.M.; LUDWIG, F. Acúmulo de nutrientes em gérbera de vaso em função de fontes e doses de potássio. Horticultura Brasileira, Vitória da Conquista, v.30, n.2, p.201-208, 2012.

LIN, W.C.; FRENCH, C.J. Effects of supplementary lighting and soil warming on flowering of three gerbera cultivars. HortScience, Alexandria, v.20, n.2, p.271-273, 1985.

LUDWIG, F.; GUERRERO, A.C.; FERNANDES, D.M.; VILLAS BOAS, R.L. Análise de crescimento de gérbera de vaso conduzida em diferentes substratos. Horticultura Brasileira, Brasília, v.28, n.1, p.70-74, 2010a.

LUDWIG, F.; FERNANDES, D.M.; MOTA, P.R.D.; VILLAS BOAS, R.L. Crescimento e produção de gérbera fertirrigada com solução nutritiva. Horticultura Brasileira, Brasília, v.28, n.4, p.424-429, 2010 b.

LUDWIG, F.; GUERRERO, A.C.; FERNANDES, D.M.; VILLAS BOAS, R.L.; LASCHI, D. Qualidade de cultivares de gérbera de vaso em função das características físicas e químicas dos substratos. Revista Brasileira de Horticultura Ornamental, Campinas, v.17, n.2, p.141$148,2011$.

MERCURIO, G. Gerbera cultivation in greenhouse. De Kwakel: Schreurs, 206p. 2002. NOORDEGRAAF, C.V. Production and marketing of high quality plants. Acta Horticulturae, Wageningen, v.353, p.134-147, 1994.

PARIZI, A.R.C.; PEITER, M.X.; ROBAINA, A.D.; SOARES, F.C.; VIVAN, G.A.; RAMÃO, C.J. Níveis de irrigação na cultura do kalanchoe cultivado em ambiente protegido. Ciência Rural, Santa Maria, v.40, n.4, p.854-861, 2010.

PAPADOPOULOS, A.; MALOUPA, E.; PAPADOPOULOS, F. Seasonal crop coeficient of gerbera soilless culture. Acta Horticulturae, Wageningen, v.408, p.81-90, 1995.

PEREIRA, J.R.D.; CARVALHO, J.A.; PAIVA, P.D.O.; SILVA, E.L.; FAQUIN, V. Efeitos da época de suspensão da fertirrigação e níveis de reposição de água na cultura do crisântemo (Dendranthema grandiflora). Ciência e Agrotecnologia, Lavras, v.27, n.3, p.658-664, 2003.

RADICE, S.; MARCONI, P.L. Clonación in vitro de diversos cultivares de Gerbera jamesonii a partir de capítulos florales. Revista de la Facultad de Agronomía, La Plata, v.103, n.2, p.111-118, 1998.

ROGERS, M.N.; TJIA, B.O. Gerbera production for cut flowers and pot plants. Portland: Timber Press, 116p. 1990. 
SAHIN, U.; ANAPALI, O. Addition of pumice affects physical properties of soil used for container grown plants. Agriculturae Conspectus Scientificus, Zagreb, v.71, n.2, p.59-64, 2006.

SANTOS, R.F.; CARLESSO, R. Déficit hídrico e os processos morfológico e físiológico das plantas. Revista Brasileira de Engenharia Agrícola Ambiental, Campina Grande, v.2, n.3, p.287-294, 1998.

SONNEVELD, C.; ELDEREN, C.W. Chemical analysis of peaty growing media by means of water extraction. Communication on Soil Science and Plant Analysis, New York, v.25, n.19/20, p.3199-3208, 1994.

TAIZ, L.; ZEIGER, E. Fisiologia Vegetal. 4a . ed. Porto Alegre: Artmed, 819p. 2009. 